\title{
ON PASSIVE NOMINALS
}

\author{
JUNJI HAMAMATSU \\ University of Tokyo
}

\begin{abstract}
The focus of this paper concerns the internal structure of the so-called "passive" nominal. It has been suggested that movement occurs in noun phrases as well as in sentences and that apparent discrepancies between the two categories originate from general principles of grammar. The present work reveals that the movement analysis cannot offer any reasonable account for some semantic constraints observed in noun phrases. It is argued that the uniform assignment of a Possessive $\theta$-role triggers those restrictions. As a result, our approach requires that the putative objecthood of prenominal genitive NPs not be represented by means of movement. ${ }^{*}$
\end{abstract}

\section{Introduction}

Since Chomsky's (1972) pioneer work "Remarks on Nominalization", the study of noun phrases has vigorously been focused on their structural parallelism with sentences. Below are the classic examples illustrating the point:

(1) a. the enemy's destruction of the city

b. the enemy destroyed the city

c. the city's destruction by the enemy

d. the city was destroyed by the enemy

Chomsky proposed that lexical heads $\mathrm{V}$ and $\mathrm{N}$ each belong to an underspecified category, thus capturing lexical and syntactic properties common to both of the categories. Anderson (1979) developed his

* This paper is based on my MA thesis submitted to the University of Tokyo. I express my profound gratitude to Professor Kinsuke Hasegawa, Professor Takane Ito and Professor Tadao Kubouchi for their invaluable suggestions and continuous encouragement. I am also indebted to two anonymous $E L$ reviewers for instructive comments. I owe a great deal to Dr. George Huges, who generously cooperated in grammaticality judgement. Finally, but not least, I appreciate Jiro Inaba and Toshinori Ito at the University of Tokyo. Needless to say, I am solely responsible for any remaining error and inadequacy.

English Linguistics 12 (1995) 1-22 - 1-

(C) 1995 by the English Linguistic Society of Japan 
idea, claiming the existence of a "passive" NP. She argued that different positions in NPs can be related via movement, in the same manner as generally assumed in the sentence. According to her view, just as (1b) and (1d) are structurally related, (1c) also can be reckoned to be a passive version of (1a). No doubt this enormously contributed to the establishment of the parallelism between the two categories, confirming the view that Move $\alpha$ applies in sentences and in noun phrases alike.

Positing movement in noun phrases seems to be a natural and desirable assumption that benefits the spirit of pursuing the purported parallelism between noun phrases and sentences to the hilt. However, clearer thinking calls for another fact to be recognized; in reality, the movement analysis causes serious empirical disadvantages. The aim of this paper is to reveal persuasive pieces of evidence against positing movement in noun phrases, denying the movement analysis of the construction dubbed "passive" nominal. ${ }^{1}$ Especially, we will attempt to provide a viable alternative to a semantic constraint that goes with the movement analysis of the construction.

\section{Constraints on Movement in Noun Phrases}

Chomsky (1986) presents an elaborate formulation of movement in noun phrases. He assumes that of is a realization of genitive Case, with Poss-insertion applied when of-insertion fails to occur. This is illustrated in (2):

(2) D-s

[(the)]

destruction [the city]

genitive Case and $\theta$-role

S-s the

destruction [of the city]

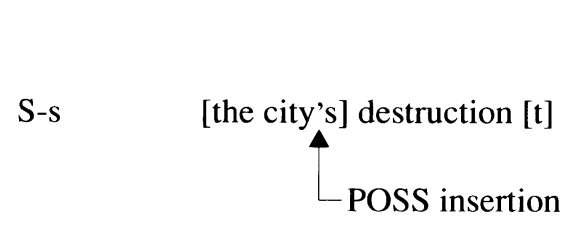

1 We use the term "passive nominal" simply because it is at once convenient and well-established; it should not be taken as endorsement of any movement analysis of the construction in question. 
Yet it is important to note that the putative movement in nominals, even if it were possible, could take place only under limited circumstances. First, some sorts of movement that can freely occur in the sentence are not allowed in noun phrases:

(3) a. *Mary's belief $t$ a genius by John (cf. Mary is believed $t$ a genius by John)

b. * Mary's appearance $t$ to have left (cf. Mary appears $t$ to have left)

Despite these apparent counterexamples, advocates of the movementbased approach maintain that movement freely occur in both sentences and noun phrases, attributing the non-occurrence to some general principle of grammar. Let us take a look at Chomsky's explanation, which has won general acceptance. In order to account for the failure of movement in such examples as (3), he formulates the "Uniformity Condition" in (4):

\section{(4) Uniformity Condition}

If $\alpha$ is an inherent Case-marker, then $\alpha$ Case-marks NP if and only if it $\theta$-marks the chain headed by NP

(Chomsky (1986: 194))

The condition requires that assignment of an inherent Case be always accompanied by $\theta$-role assignment. With this in mind, let us get back to (3). In (3a) and (3b), the Theme $\theta$-role is assigned to the embedded sentence, not to the chain (Mary, $t$ ). Thus a Case marker of fails to be inserted, which causes a Case Filter violation.

That way, the Uniformity Condition successfully excludes the incorrect instances of movement in noun phrases. This is only half of the problem, however. The trouble is that even the simplest cases of movement cannot be exempted from severe constraints. Consider what creates the following contrasts, discussed in Anderson (1979):

( 5 ) a. the city's destruction (by the enemy)

b. the mob's dispersal (by the army)

c. Carswell's confirmation (by the Senate)

(6) a. *algebra's knowledge

b. *Mary's avoidance (by Tom)

c. *the topic's discussion (by the students)

The difference between (5) and (6) is, Anderson argues, due to the degree of "Affectedness"; nominal complements within noun phrases cannot be preposed unless they are affected arguments, specifically, "changed or moved by the action of the head nominal" (Anderson 
(1979: 44)). This has been known in the literature as the "Affectedness Constraint" and still continues to play a central role in the study of nominalizations.

Admittedly, the adequacy of the Affectedness Constraint has often been called into question. ${ }^{2}$ That apart, what is important with respect to our main discussion is that such contrasts as observed in noun phrases are not attested in sentences; all the sentential counterparts of (6) are completely grammatical:

( 7 ) a. Algebra is known

b. Bill was avoided (by John)

c. The topic was discussed (by the students)

One might naturally ask here why the Affectedness Constraint manifests itself in noun phrases, but not in sentences. In other words, if the semantic restraint is imposed on movement, it ought to void movement in (7) as well as that in (6). That this is not the case casts doubt on the assumption that the Affectedness Constraint is a semantic restriction imposed on the passive movement in the case of noun phrases.

Much attention must be paid to that striking discrepancy between noun phrases and sentences. I presume that it can reasonably be ascribed to the difference in the way $\theta$-roles are assigned in each category. Let us first consider the case of the sentence. On the VPinternal subject hypothesis, external $\theta$-role assignment in the sentence can be illustrated as (8):

( 8 )

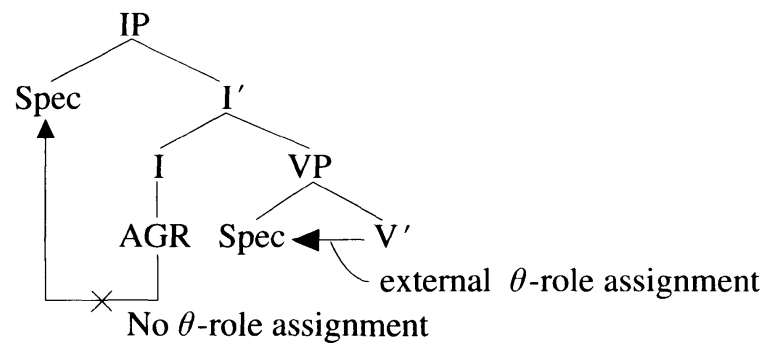

The NP in [Spec, VP] is assigned the external $\theta$-role of the verb, moving to [Spec, IP] in order to get Case. Crucially, AGR in I assigns nominative Case but no $\theta$-role to the specifier position of the IP.

2 However, this problem is such a recalcitrant one that to my knowledge, no one has offered a satisfactory alternative to the mysterious semantic restriction. See Taylor (1994) for discussion. 
Thus, the external $\theta$-role of the verb is assigned straightforwardly without restraints.

This seems not to be the state of affairs in noun phrases. Adopting the PossP projection first proposed by Anderson (1983), I claim that a Possessive $\theta$-role is assigned when genitive Case assignment occurs in the prenominal position. This is depicted in $(9):^{3}$

(9)

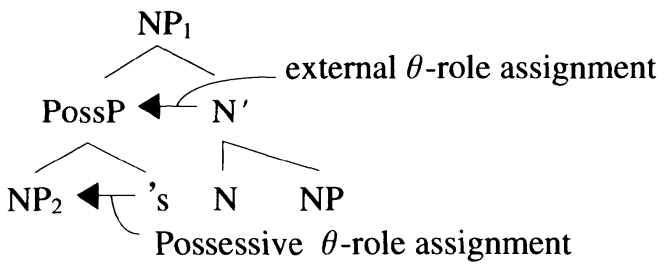

In (9), $\mathrm{N}^{\prime}$ assigns a certain $\theta$-role to the Spec of the $\mathrm{NP}_{1} \cdot{ }^{4}$ At the same time, the Possessive $\theta$-role is assigned to the $\mathrm{NP}_{2}$, which is a complement of the genitive marker 's. ${ }^{5}$ We further suppose that this

3 We have adopted here the NP structure rather than the DP structure, for the latter apparently seems to be incompatible with our approach. We will not discuss at length the adequacy of the choice in this paper, but take a brief look at this problem in note 21 .

${ }_{4}$ Notice here that the external $\theta$-role is assigned within the NP. Adopting the VP-internal subject hypothesis makes the manner of the external $\theta$-role assignment in the NP parallel to the one in the sentence, where the external $\theta$-role is assumed to be assigned to [Spec, VP]. I am grateful to one anonymous $E L$ reviewer for bringing this point to my attention.

5 Adopting the framework of Anderson (1983), we consider the NP+'s construction to be a postpositional phrase headed by 's. This is plausible, for it can take any NP as its complement:

(i) [NP [PossP [NP the man I met yesterday]'s] car]

True, the PossP might conflict with the X-bar theory, because English is rigidly a head-initial language. When it comes to pre-modifiers, however, this seems not to be the case. Williams (1982a) posits the head-final filter, which states that premodifying expressions must be head-final, and hence cannot involve post-modifiers. First, this is justified by such contrasts as (ii):

(ii) a. an environment [free of pollution]

b. a [pollution free] environment

c. *a [free of pollution] environment

(Radford (1993: 83))

Also, it correctly accounts for data like the following in German, adopted from Radford (1993), who cites them from Lyons (1991):

(iii) a. eine [auf sich stolze] Frau an of herself proud woman

b. *eine [stolze auf sich] Frau a proud of herself woman

That way, Williams' generalization is empirically supported. 
$\theta$-role semantically crashes with some kinds of $\theta$-roles, which brings about the Affectedness Constraint. Let us formulate this as (10):

(10) The Possessive Constraint

NPs are illegitimate (at LF) if they occur as the complement of Poss whose maximal projection is assigned an Unaffected Theme $\theta$-role.

As it stands, however, the above formulation is nothing but a stipulation. We must show why Unaffected Theme is incompatible with the Possessive $\theta$-role. Admittedly, this is such a formidable task that we cannot fully accomplish it in this present study. To illustrate, take the contrast between (5a) and (6a) for example. It is natural to say "the destruction that the city had", while "the knowledge that algebra has" is a sheer nonsense. Thus, the city in the former example can be considered to qualify as a possessor, whereas algebra in the later cannot. Considering this contrast, I believe we are broadly on the right track. ${ }^{6}$

We are now in a position to examine how the PossP and the Possessive Constraint conspire to explicate such contrasts as (11) under consideration:

(11) a. the city's destruction (by the enemy) (=5a)

b. *algebra's knowledge $(=6 a)$

The structures of (11) would be schematized as the following:

(12) [NP [PossP [NP the city] 's] destruction]

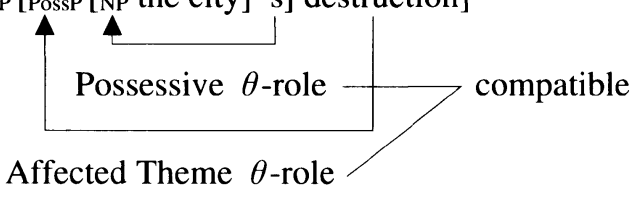

6 Although no reference is made to ungrammatical cases, the suggestion of Poutsma (1914) is practically on the same track as ours. He says:

... the objective relation is sometimes mixed with the relation of possession understood in its widest sense ... Thus such combinations as Marley's funeral, the king's accommodation, the lady's amusement may also be interpreted: the funeral which Marley had, the accommodation which the king had, the amusement which that lady had. These and similar combinations may favor the use of others, such as Rizzo's assassination, Elenor's banishment, her daughter's loss etc. where the relation of possession cannot be thought of.

(Poutsma (1914: 24.20)) 
(13)

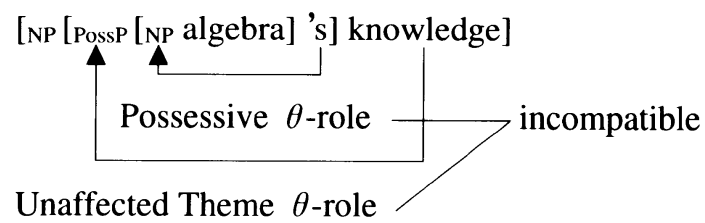

In (12), $\mathrm{N}^{\prime}$ assigns Affected Theme to the PossP, while the genitive 's assigns a Possessive $\theta$-role to the NP in the PossP. The derivation is legitimate, since Affected Theme is thematically compatible with the Possessive $\theta$-role. On the other hand, in (13), $\mathrm{N}^{\prime}$ assigns Unaffected Theme to the PossP. The Possessive Constraint predicts that the Possessive $\theta$-role discharged by the genitive 's thematically collides with the Unaffected Theme $\theta$-role. As a result, the whole NP is judged as ungrammatical.

Notice that our approach is unique in that it assumes that the genitive morpheme 's acts as a $\theta$-role assigner as well as a Case marker, but never as a semantically null Case assigner. ${ }^{7}$ By contrast, movement analysis of passive nominals cannot take this option, because movement must always be to a non- $\theta$-position; otherwise, the movement triggers a violation of the $\theta$-criterion. Examining the PossP approach in this light, we can say that by virtue of considering the genitive 's to be a $\theta$-role assigner, the approach principally excludes any A-movement to [Spec, NP]. In consequence, incorrect instances of raising in noun phrases such as (3) are also prohibited.

\section{Support for the PossP and the Possessive Constraint}

In the last section, we have proposed the PossP and the Possessive Constraint on the basis of observations concerning the passive nominal. This section presents some pieces of evidence for these hypotheses.

\subsection{Preposed Objects as Possessors 8}

Preposed objects of nouns, though they are perceived as apparent complements of derived nouns, behave in the same manner as possessive NPs modifying non-derived nouns. Examples in $\left(14 \mathrm{a}^{-} \mathrm{c}\right)$ are

7 Note that Anderson (1983) assumes the PossP only in cases of non-derived nominals. For passive nominals, she remarks that they involve semantically null genitive Case assigner.

8 For the term "preposed object", it is merely for convenience. See also note 1. 
from Taylor (1989: 674):

(14) a. the man's release from prison

*the information's release from the government

b. Poland's invasion

?my privacy's invasion

c. America's discovery

* our common interest's discovery

d. the man's picture

*the flower's picture

Objects which are non-animate or have no close relationship with human activities usually tend not to appear in the prenominal genitive form of passive nominals. ${ }^{9,10}$ As is well known, this restriction is generally observed in cases of non-derived nominals:

a. ?*the house's roof

(cf. the roof of the house)

b. the boy's foot

*?the mountain's foot

(cf. the foot of the mountain)

Thus, preposed objects and other sorts of genitive NPs conform to the same constraint concerning animacy (and human activity).

There is another piece of syntactic evidence of this kind. Let us examine the examples in (16):

9 In fact, Grimshaw (1990: 93) observes that unlike cases of possessive NPs with non-derived nouns, animateness has nothing to do with preposed objects. However, she adduces no concrete examples. The examples in (14) prove that the opposite is true. Granted, such examples as those in the following at first blush might seem to pose problems, as an anonymous $E L$ reviewer pointed out:

(i) the poem's translation by John (Anderson (1979: 44))

(ii) the city's destruction by the enemy

Yet these prenominal genitive NPs have close relationship with human activities, which licenses the prenominal genitive form. Indeed, the same NPs can occur with ordinary nouns:

(iii) the poem's importance

(iv) the city's highest building

10 Such occurrences as yesterday's lecture and last year's election are problematic. Indeed, temporal nouns can appear very freely in the genitive form. We ignore this problem here, merely mentioning that highly abstract nature of Possessive $\theta$ role permits such interpretations as "Yesterday had the lecture" and "Last year had the election". See Abney (1987: 102) for discussion, who advocates this view as well. 
(16)
a. ??the tree's removal by Mary
(Grimshaw (1990: 87))
b. ??the food's digestion by worms
(Grimshaw (1990: 87))
c. ??the scandal's erasure by the authorities

Strikingly, the acceptability of the preposed objects in (16) is considerably upgraded by substituting its for each full genitive NP, as pointed out by Grimshaw (1990: 87). She cites the examples in $(17 a-c)$ from Kayne (1984):

(17) a. its removal by Mary

(Kayne (1984: 137))

b. its digestion by worms

(Kayne (1984: 137))

c. its erasure by the authorities

(Kayne (1984: 138))

Interestingly enough, I would like to point out, exactly the same contrast is attested in non-derived nominals as well:
a. its roof
$?^{*}$ the house's roof
b. its foot
*?the mountain's foot

Note in passing that we can obtain exactly the same effect by using whose instead of its. First, consider cases of derived nouns:

(19) a. *algebra's knowledge

b. ??the scandal's erasure by the government

c. the language whose knowledge is vital to the study of the novelist

d. the scandal whose erasure saved the politician from accusation

The deviancy of (19a) and (19b) disappears if each full genitive NP is replaced by whose. The same sort of improvement is observed in instances of non-derived nouns:

(20) a. *?the mountain's foot

b. ?*the house's roof

c. the mountain whose foot is crowded with sightseers

d. the house whose roof is red

Thus, whose substitution gives rise to the same kind of improvement as that caused by its substitution.

The most straightforward way to account for the above phenomena is to assume that preposed objects and other kinds of genitive NPs alike are generated in the form of PossPs. We can thus conclude that the Possessive $\theta$-role triggers the degraded acceptability. The improvement in (17) will be explained if we regard its not as a PossP but as an NP containing no Possessive $\theta$-role assigner. The structure of (17a), 
for instance, would then be the one given in $(21):{ }^{11}$

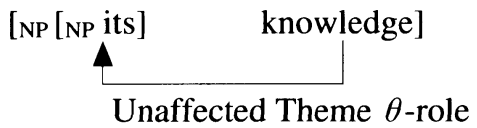

No Possessive $\theta$-role assigner is present in (21), and hence only the Unaffected Theme assigned by $\mathrm{N}^{\prime}$ is relevant. Consequently, no semantic restraints such as Affectedness are imposed on this kind of construction. ${ }^{12,13}$ We also take whose in (19) as an NP, not a PossP.

\subsection{Further Restrictions on the Spec of NPs}

As a matter of fact, the Affectedness Constraint is not the sole thematic restriction that is imposed on the Spec of NPs. There are at least two other restrictions of that ilk. One concerns the behavior of nouns derived from emotive verbs, suggested by Rappaport (1983). Let us examine (22):
a. *the film's amazement of the audience
Experienced Experiencer
(cf. The film amazed the audience)
b. *the news' shock of John
Experienced
Experiencer
(cf. The news shocked John)
c. *the devil's fright of Mary
Experienced
Experiencer
(cf. The devil frightened Mary)

As opposed to their sentential analogues, nominals do not allow arguments bearing an Experienced $\theta$-role to appear as subjects of NPs. Let us dub this the Experienced Constraint.

11 Their, the plural form of its, behaves in line with its, as the complete acceptability of the following example shows:

(i) He must learn both Russian and Polish, because their knowledge is indispensable to his research.

12 Presumably, such instances as (18) and (20) can also be explained in a similar fashion.

13 Note, however, that all the other pronominals apparently trigger no such grammatical improvement as its produces:

(i) *your knowledge (your $=$ Theme)

(ii) ${ }^{*}$ his $/{ }^{*}$ her sight (his/her $=$ Theme)

(iii) ${ }^{*}$ my description (my=Theme)

We therefore conclude that these pronominal genitives contain PossP projections. 
The other is a constraint on the Instrument $\theta$-role. Rozwadowska (1988) shows that an NP bearing this $\theta$-role causes grammatical degradation:

\section{a. ?the key's opening of the door Instrument \\ (cf. The key opened the door) \\ b. ?? the knife's damage of the table \\ Instrument \\ (cf. The knife damaged the table)}

Once again, degraded grammaticality is observed in nominals, while their sentential equivalents are completely acceptable. This provides us with another case of constraint on the Spec of NPs, although the ungrammaticality is substantially milder than in the case of the Experienced $\theta$-role. We call this the Instrument Constraint.

At this point, it is desirable to generalize the three kinds of constraints into some general restraint. Indeed, Rozwadowska develops her argument on this line. First, she assumes the thematic label "Neutral" (or "N-role"), which is defined as (24):

(24) An entity $X$ holds a thematic relation $\mathrm{N}$-role with respect to a predicate $\mathrm{Y}$ if

(i) $\mathrm{X}$ is in no way affected by the action, process, or state described by $\mathrm{Y}$,

(ii) $\mathrm{X}$ does not have any control over the action, process, or state described by $\mathrm{Y}$.

(Rozwadowska (1988: 151))

According to her definition, Unaffected Theme and Experienced both can be comprised in $\mathrm{N}$-role, and Instrument has an intermediate status between Agent $\theta$-role and $\mathrm{N}$-role. She then formulates " $\mathrm{N}$-rule" as in (25):

(25) N-Rule

Neutral cannot appear in specifier position of a nominal

(Rozwadowska (1988: 151))

This rule prevents Unaffected Theme and Experienced from acting as the subject of an NP. The slightly degraded acceptability of the Instrument in [Spec, NP] is attributed to its marginal status between Agent and Neutral.

Rozwadowska thus establishes that non-occurrence of some kinds of arguments in the subject of an NP can be ascribed to the general constraint imposed on that position. In her work, however, no 
clarification is made on what triggers such restrictions on the specifier of an NP. Our assumption of the Possessive $\theta$-role assigned to that position furnishes the answer; by the analogy of the case of the Affectedness Constraint, it is reasonable to maintain that the Experiencer and the Instrument Constraints also have their roots in Possessive $\theta$-role assignment peculiar to noun phrases. This is plausible, because those constraints are observed solely in noun phrases, just as in the case of the Affectedness Constraint.

Recall here that the Affectedness effect evaporates when we substitute its or whose for a full genitive NP. As a natural extension, the Experienced and the Instrument Constraint effect is also expected to disappear when we replace a full genitive NP with its or whose, so long as the restriction is assumed to be triggered by a Possessive $\theta$ role. This forecast is evidenced by (26):

(26) a. its amazement of the audience

b. the miracle whose amazement of the audience was so terrific

c. its damage of the table

d. the knife whose damage of the table was terrible

The acceptability of Experienced and Instrument arguments in [Spec, $\mathrm{NP}$ ] improves to a great extent in (26). Clearly, the grammatical amelioration is due to the lack of a Possessive $\theta$-role assigner; since its and whose both carry no Possessive $\theta$-role assigner, they cause no such semantic effect as their full genitive NP equivalents in (22) and (23) do.

Thus, we conclude that the three constraints can be integrated in terms of Possessive $\theta$-role assignment. Revising the initial formulation in (10), let us integrate them into (27):

(27) The Possessive Constraint

NPs are illegitimate (at LF) if they occur as the complement of Poss whose maximal projection is assigned an Unaffected Theme/Experienced/Instrument $\theta$-role.

We now face exactly the same problem we tackled in formulating (10), the original version of (27): we must offer an explanation for the reason Experienced and Instrument are respectively incompatible with the Possessive $\theta$-role. Consider the contrast below:

(28) a. the people's amazement at the film Experiencer

b. *the film's amazement of the audience $(=22 \mathrm{a})$ Experienced 
Experiencer is compatible with the Possessive $\theta$-role, while Experienced is not. This contrast is paralleled by the following contrast:

(29) a. The people had a great amazement.

b. *The film had a great amazement.

We regard this as support for the assumption in (27) that the Experienced $\theta$-role is not licensed for one of the associations that qualify as possession. ${ }^{14}$

The three constraints at issue now fall under the postulation in (27); they thematically collide with the Possessive $\theta$-role, which causes the observed ungrammaticality. The restriction in (27) thus offers a reasonable, if not yet principled, account for some idiosyncrasies of nominals by ascribing the thematic restrictions to the genitive morpheme 's, which is present solely in noun phrases.

\subsection{Contrasts between Germanic and Romance Noun Phrases}

Romance and Germanic noun phrases exhibit quite a stimulating contrast in their behavior with respect to the Affectedness Constraint. For starters, note that in Romance noun phrases only pronominals can appear as prenominal genitives, whereas full genitive NPs are expressed by means of prepositions and hence occur in the postnominal position:
a. il mio libro (Italian)
the my book
'my book'
b. mon livre (French)
my book
c. il libro di Gianni (Italian)
the book of Gianni
'Gianni's book'
d. le livre de Jean (French)
the book of Jean
'Jean's book'

As shown above, these languages have no analogues of the English genitive marker 's. The entire absence of such a morpheme naturally leads us to assume that those pronouns contains no PossP. It is there-

14 Regrettably, it is not all clear to me why Instrument conflicts with the Possessive $\theta$-role. We leave this puzzle for further research, realizing that the Possessive Constraint as a whole also requires more refinement. 
fore expected that there are no such semantic constraints as the Affectedness Constraint. This prediction is born out in (31): ${ }^{15}$

a. *the novel's understanding

b. A proposito di quel romanzo, la sua comprensione to purpose of the novel the its comprehension richiede notevoli capacita ermeneutiche (Italian) requires remarkable capacity hermeneutic 'Concerning that novel, its understanding requires remarkable hermeneutic skills'

c. (Ce probleme est tres difficile.) $S a$ comprehension the problem is very difficult its comprehension exige beaucoup de travail (French) needs much of work '(The problem is very difficult.) Its understanding needs a lot of work'

(Giorgi and Longobardi (1991: 142))

Clearly, the English example in (31a) is excluded by the Affectedness Constraint, or by the Possessive Constraint in our approach. By contrast, no such restraints are observed in French or Italian examples in (31b) and (31c). This immediately follows if we assume that a Possessive $\theta$-role is not assigned to [Spec, NP] in those languages, a direct consequence of the absence of a PossP.

Since no Possessive $\theta$-role assigner is available in Romance noun phrases, a nominal brand of passive movement may be a possibility in those languages. Consider the derivation of sa comprehension in

15 An anonymous EL reviewer suggested to me that the argument here was problematic, because also in English its understanding is judged grammatical, as pointed out earlier in the text. Still, as noted in note 13, pronominal genitives other than its do not permit Theme reading in English. Conversely, in Romance languages, they are eligible for Theme interpretation. Consider the Italian examples below:

(i) la sua vista $($ sua $=$ Theme) the his sight

(ii) la mia descrizione $(\mathrm{mia}=$ Theme $)$ the my description

(Giorgi and Longobardi (1991: 141))

(Giorgi and Longobardi (1991: 37)) In contrast to their English congeners in note 13, pronominal genitives in the above instances trigger no Affectedness effect. This evidences that our argument in the text for the lack of PossPs in Romance languages is tenable. 
$(31 \mathrm{c}):^{16}$

$$
\text { D-s [spec e] comprehension [NP sa] }
$$

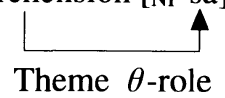

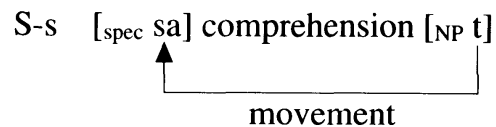

In (32), the head noun assigns a $\theta$-role to its complement, which subsequently is moved to the subject of the whole NP. Crucially, no $\theta$-role is assigned to the prenominal position, so the resultant chain $(s a, t)$ is legitimate, with $s a$ assigned genitive Case and $t$ a Theme $\theta$ role. The derivation therefore causes no such problems as its English equivalent does. Thus, the unreserved occurrences of preposed objects in Romance nominals are shown to originate in the lack of a Possessive $\theta$-role assigner in those languages.

In contrast to the case of the Romance nominal, Germanic noun phrases permit full NPs to occur prenominally in the genitive form. Therefore, morphologically at least, nothing prevents us from positing PossPs in nominals of those languages. And if they behave just as English NPs with respect to the constraints on the Spec of NPs, the employment of the PossP will be empirically justified. This is actually the case. Consider the Norwegian examples below:

$$
\begin{aligned}
& \text { a. forståelsen av problemet (Norweigian) } \\
& \text { the understanding of the problem } \\
& \text { b. *problemets forståelse } \\
& \text { the problem's understanding }
\end{aligned}
$$

(Giorgi and Longobardi (1991: 142))

As exemplified above, Theme reading of the prenominal genitives in (33) is impossible in Norwegian. This immediately reminds us of the incorrect English examples such as (6), repeated as (34):
a. *algebra's knowledge
b. *Mary's avoidance (by Tom)

16 Following Giorgi and Longobardi (1991: 163), we adopt the view that this movement is motivated by the necessity for possessive pronouns to be licensed by Spec-Head agreement. 


$$
\text { c. *the topic's discussion (by the students) }
$$

They were attributed to the Affectedness Constraint, or in our terms, to the Possessive Constraint. By analogy, we can resort to the same procedure in handling the Norwegian example. Assuming a PossP, the structure of (33b) can be depicted as (35):

(35) [NP [PossP [NP problemet] s] forståelse]

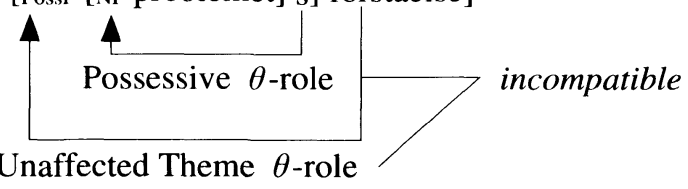

The noun forstaelse assigns the PossP Unaffected Theme, which is thematically incompatible with the Possessive $\theta$-role assigned by the genitive morpheme, as the Possessive Constraint predicts. Thus, the ungrammaticality of (33) is accounted for in the same manner as that of its English analogue.

That way, Germanic noun phrases behave in harmony with their English counterparts, and hence the prediction made concerning the latter can be extended directly to the former. That is, the Affectedness effect follows from the assumptions of the PossP and the Possessive Constraint.

\section{4. $\theta$-Role Assignment in Noun Phrases}

So far we have seen that the PossP and the Possessive Constraint conspire to account for the wide range of phenomena concerning some constraints on the noun phrase. We are now in a position to elaborate the structure of the passive nominal in our framework. In this section, we investigate at length how $\theta$-roles are assigned in English genitive constructions.

\subsection{The Compositional $\theta$-Marking in Noun Phrases}

The cardinal point in our approach is that, when a genitive Case marker 's appears, a Possessive $\theta$-role is mandatorily assigned to the NP complement of Poss in addition to the $\theta$-role assigned to [Spec, $\mathrm{NP}$ ] by $\mathrm{N}^{\prime}$. One might naturally wonder if this causes a violation of the $\theta$-criterion. Marantz's (1984) $\theta$-marking mechanism, adopted and adjusted by Rizzi (1990), serves the purpose of shunning the $\theta$ criterion violation under the circumstances. To begin with, consider the $\theta$-marking of PPs selected by verbs. Take the VP give a book to 
John for example. We must then somehow express the fact that the verb give has a $\theta$-grid including the role Goal and that this role is directly assigned to John by the preposition to. Rizzi, modifying Marantz's framework, adopts the following technique: the verb assigns a $\theta$-role $\left(\theta_{1}\right)$ to a selected $\mathrm{PP}$, and this $\theta$-role must (thematically) match the one assigned by the head of the PP to its object $\left(\theta_{2}\right)$, as depicted in (36):

give (a book) [pP to [NP John]]

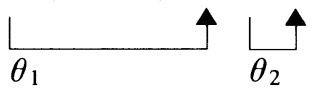

indirect $\theta$-marking direct $\theta$-marking

Let us apply this to the noun phrase. The NP version of the $\theta$ marking system would be as (37):

(37)

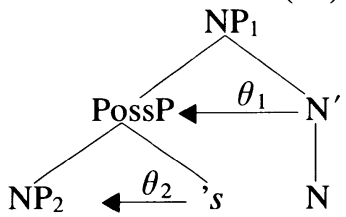

$$
\begin{aligned}
& \theta_{1} \text { : indirect } \theta \text {-marking } \\
& \theta_{2} \text { : direct } \theta \text {-marking (Possessive } \theta \text {-role) }
\end{aligned}
$$

In (37), the $\theta$-role $\left(\theta_{1}\right)$ that the $\mathrm{N}^{\prime}$ indirectly assigns to the Poss $\mathrm{P}$ in the Spec of the $\mathrm{NP}_{1}$ must be thematically compatible with the Possessive $\theta$-role $\left(\theta_{2}\right)$ that the genitive morpheme 's directly assigns to its complement. This seems plausible if we reasonably assume that PossPs are equivalent to PPs in that the Poss head, namely, the genitive 's directly assigns a $\theta$-role to its complement NP in the same way $\mathrm{P}$ assigns some $\theta$-role to its complement. Let us call this the Compositional $\theta$-marking System (CTS henceforth).

\subsection{Passive Nominal as a Result Nominal}

We now need to examine the nature of the $\theta$-role assigned by $\mathrm{N}^{\prime}$ to the PossP. In some cases, this amounts to an external $\theta$-role, but as is well known, this is not always the case in the noun phrase. Grimshaw (1990) suggests that nominals are divided into two types: "event" and "result" nominals. She argues that the former has an argument structure, while the latter does not. This distinction can be evidenced through a variety of syntactic tests. Briefly put, the representative distinction measures are as follows: Only the event 
nominal can licence (i) modifiers like frequent and constant, (ii) the same modifiers as their original verbs and (iii) purpose phrases, while (iv) only the result nominal can pluralize.

Grimshaw also utilizes the event/result distinction for analyzing the passive nominal, reporting quite an intriguing array of facts. Drawing heavily on the fruitful result of her work, let us examine the passive nominal in terms of the event/result distinction. Let us begin with (38):

(38) a. the frequent / constant nomination of the politician b. *the politician's frequent/constant nomination

(Grimshaw (1990: 83))

(38a) shows that the noun nomination can qualify as an event noun. By contrast, (38b) indicates that its passive equivalent is not compatible with event reading.

Second, passive nominals cannot occur with aspectual modifiers, as (39b) and (39d) imply:

(39) a. the construction of the building in three weeks

b. *the building's construction in three weeks

c. John's translation of the book in only three months

d. *the book's translation in only three months

(Grimshaw (1990: 83))

Next, passive nominals are not compatible with purpose phrases, either:

(40) a. the destruction of the city in order to prove a point

b. *the city's destruction in order to prove a point

Finally, passive nominals can occur in the plural form, in contrast with the case of a noun with an of-phrase:

(41) a. *the nominations of the politician

b. the politician's nominations

(Grimshaw (1990: 83))

All this reveals that the passive nominal should be classified as a result nominal. It follows then that passive nominals are void of argument structures and hence $\theta$-marking capacity. This in turn means that the $\theta$-role assigned to the object NP in passive nominals is not Theme. Now that the objecthood cannot be represented via assignment of a Theme $\theta$-role, the question arises of what gives the preposed NP the flavor of objecthood. 


\subsection{Relation $\mathrm{R}$}

Williams (1982b) claims that the apparent objecthood of a preposed $\mathrm{NP}$ in the passive nominal should be understood as one of the vast array of meanings that the specifier position of an NP can represent. To illustrate, consider the examples below:
a. John's car
b. Tom's school
c. the city's destruction by the army

The meaning that (42a) can represent is never confined to that of possession like "the car John owns". Besides, it can depict manifold situations. To name but a few, "the car John drives", "the car John stole" and "the car John likes". In (42b), the appropriate meaning that comes first to our mind is something like "the school Tom goes to", rather than a possessive meaning like "the school Tom owns". Thus, according to Williams, passive movement need not be assumed in (42c), for its putative Theme meaning can be perceived as one instance of the broad range of associations that hold between the specifier position and the head noun.

Higginbotham (1983) proposes that modifiers of nouns, including possessive NPs, are assigned "relation R" to the head noun, which is not confined to one particular $\theta$-role. ${ }^{17}$ To be specific, any relation $\mathrm{R}$ can hold between the argument in the Spec of NP and the head noun. The interpretation of relation $R$ is contextually determined by the relation that holds between the head noun and the specifier of the whole NP in each case. That way, Williams and Higginbotham are broadly on the same track in their characterization of expressing thematic relations in noun phrases. ${ }^{18}$ Let us then adopt the view that relation $\mathrm{R}$ is assigned by $\mathrm{N}^{\prime}$ to [Spec, NP] in the passive nominal. The relation $\mathrm{R}$ in this case receives an interpretation of Theme, which provides the prenominal NP with the scent of an object. For illustration, consider the contrast between the city's destruction and *algebra's knowledge. In the former, the city receives the relation $\mathrm{R}$ interpreted as Affected Theme. By contrast, the relation $\mathrm{R} \theta$-role

17 Still, Higginbotham assumes that relation $\mathrm{R}$ does count for satisfaction of the $\theta$-criterion. We accept his claim.

18 To be precise, Williams' proposal differs from relation $\mathrm{R}$ in that he regards the Spec of NP as a non- $\theta$-position. We assume, albeit his argument, that the Spec of an NP is a $\theta$-position. 
assigned to algebra gets an interpretation of Unaffected Theme. Thus, the Possessive Constraint rules this out. ${ }^{19,20}$

\section{Concluding Remarks}

This study of the passive nominal has shown that the objecthood that a prenominal genitive NP in the construction bears need not be represented by means of passive movement, as assumed in Anderson (1979) and Chomsky (1986), among others. Instead, we have constructed a framework composed of the PossP, the relation $\mathrm{R}$ and the CTS. Its final version can be depicted as (43): ${ }^{21}$

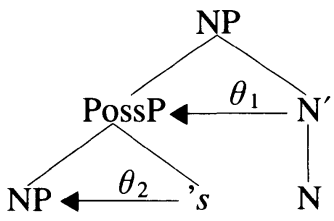

$\theta_{1}$ : relation $\mathbf{R}$

$\theta_{2}$ : Possessive $\theta$-role

19 Crucially, relation $\mathrm{R}$ is distinct from the authentic Theme $\theta$-role, which is assigned in (i) and (ii):

(i) The enemy destroyed the city (Theme)

(ii) the destruction of the city (Theme)

This presumption is natural, if we consider the directionality of $\theta$-role assignment: presumably, derived nouns, together with their original verbs, should assign Theme in the right direction (see Travis (1984)). Genuine Theme $\theta$-role, therefore, should reasonably be taken to be assigned rightward, while the city in the city's destruction gets relation $\mathrm{R}$ interpreted as Theme.

20 Precisely, the unaffected Theme in the Possessor Constraint in (27) need be restated as "relation $\mathrm{R}$ interpreted as Unaffected Theme", though we will not do so for simplicity. As for Experienced and Instrument $\theta$-roles, however, they apparently do not result from relation $\mathrm{R}$. We repeat the relevant examples below:

(i) *the film's amazement of the audience

(ii) ?? the knife's damage of the table

Considering their sentential counterparts (the film amazed the audience/the knife damaged the table), in which the film and the knife are assigned Experienced and Instrument respectively, it is natural to reckon that the $\theta$-roles the prenominal genitive NPs bear in (i) and (ii) are authentic ones.

21 Let us consider whether a DP version of (41) is defensible. One possibility would be (i):

(i) [DP [DP the city $\mathrm{i}]$ [D 's] [NP [DP $\left.\mathrm{t}_{\mathrm{i}}\right]$ [ $\mathrm{N}^{\prime}$ destruction]]]

The chain (the city $\mathrm{i}_{\mathrm{i}}, t_{\mathrm{i}}$ ) is assigned a Possessive $\theta$-role in [Spec, DP] and a relation 
The relation $R$, which is assigned to the Poss $\mathrm{P}$ by $\mathrm{N}^{\prime}$, gets a Theme reading in the case of a passive nominal. In addition, the Possessive $\theta$-role is assigned to the NP within the PossP. A violation of the $\theta$ criterion is neatly avoided by virtue of the CTS assumed in (43). To posit an assignment of the Possessive $\theta$-role is necessary, because it, combined with the Possessive Constraint, offers a reasonable explanation for the semantic constraints laid down on the Spec of an NP:

(44) The Possessive Constraint

NPs are illegitimate (at LF) if they occur as the complement of Poss whose maximal projection is assigned an Unaffected Theme/Experienced/Instrument $\theta$-role.

Since no Possessive $\theta$-role is assigned in sentences, no such constraints are expected to be observed there, which is consistent with the fact. By contrast, the movement-based approach fails to account for the reason why the constraints are observed solely in noun phrases, simply stipulating that the Affectedness Constraint is imposed on movement in NPs. We thus conclude that passive movement need not and should not be assumed in noun phrases.

\section{REFERENCES}

Abney, Steven (1987) The English Noun Phrase in Its Sentential Aspect, Doctoral dissertation, MIT.

Anderson, Mona (1979) Noun Phrase Structure, Doctoral dissertation, University of Connecticut.

Anderson, Mona (1983) "Prenominal Genitive NPs," The Linguistic Review 3, $1-24$.

Chomsky, Noam (1972) "Remarks on Nominalization," Studies on Semantics in Generative Grammar, 11-61, Mouton, The Hague.

Chomsky, Noam (1986) Knowledge of Language: Its Nature, Origin, and Use, Praeger, New York.

Giorgi, Alessandra and Gluseppe Longobardi (1991) The Syntax of Noun

R $\theta$-role (interpreted as Unaffected Theme) in [Spec, NP]. Obviously, this will end up violating the $\theta$-criterion, so long as the relation $\mathrm{R}$ amounts to a $\theta$-role with respect to the jurisdiction, as mentioned in note 17 . This difficulty notwithstanding, we would not go so far as ousting the DP framework. A promising proposal with this regard is found in Szabolcsi (1994: 193), who suggests that the semantic role assignment in noun phrases should be divided into two classes. 
Phrases: Configuration, Parameters and Empty Categories, Cambridge University Press, Cambridge.

Grimshaw, Jane (1990) Argument Structure, MIT Press, Cambridge, MA.

Higginbotham, James (1983) "Logical Form, Binding, and Nominals," Linguistic Inquiry 14, 395-420.

Kayne, R.S. (1984) Connectedness and Binary Branching, Foris, Dordrecht.

Lyons, Christopher (1991) "Some Thoughts on the DP Hypothesis," ms., University of Salford.

Marantz, Alec (1984) On the Nature of Grammatical Relations, MIT Press, Cambridge, MA.

Poutsma, Hendrick (1914) A Grammar of Late Modern English, Part II, Noordhoff, Groningen.

Radford, Andrew (1993) "Head-hunting: On the Trail of the Nominal Janus," Heads in Grammatical Theory, ed. by Greville Corbett, Norman Fraser and Scott McGlashan, 73-113, Cambridge University Press, Cambridge.

Rappaport, Malka (1983) "On the Nature of Derived Nominals," Papers in Lexical-Functional Grammar, ed. by Beth Levin and Malka Rappaport, 113-142, Indiana University Linguistics Club, Bloomington, Indiana.

Rizzi, Luigi (1990) Relativized Minimality, MIT Press, Cambridge, MA.

Rozwadowska, Bozena (1988) "Thematic Restrictions on Derived Nominals," Syntax and Semantics 21: Thematic Relations, ed. by Wendy Wilkins, 147-165, Academic Press, San Diego.

Szabolsci, Anna (1994) "The Noun Phrase," Syntax and Semantics 27: The Syntactic Structure of Hungarian, ed. by Ferenc Kieter and Katalin E. Kiss, 179-274, Academic Press, San Diego.

Taylor, John (1989) "Possessive Genitives in English," Linguistics 27, 663-686.

Taylor, John (1994) "'Subjective' and 'Objective' Readings of Possessor Nominals," Cognitive Linguistics 5-3, 201-242.

Travis, Lisa (1984) Parameters and Effects of Word Order Variation, Doctoral dissertation, MIT.

Williams, Edwin (1982a) "Another Argument that Passive is Transformational," Linguistic Inquiry 13, 160-163.

Williams, Edwin (1982b) "The NP Cycle," Linguistic Inquiry 13, 277-295.

Department of English Language and Literature

Faculty of Letters

The University of Tokyo

7-3-1 Hongo, Bunkyo-ku

Tokyo, 113

e-mail: jjh@tansei.cc.u-tokyo.ac.jp 